\title{
O “LIMBO” JURÍDICO PREVIDENCIÁRIO
}

\author{
Mari Ângela Pelegrini \\ Universidade do Oeste Paulista - UNOESTE, curso de Direito, Presidente Prudente, SP. \\ E-mail: maripelegrini@uol.com.br
}

\section{RESUMO}

$\mathrm{O}$ artigo analisa as consequências jurídicas do período em que o trabalhador, após afastamento previdenciário, por sequelas comuns ou acidentárias, que exigem prévio afastamento das atividades laborais, recebe alta médica. Na sequência, supostamente sem estar apto, sofre o indeferimento da continuidade de recebimento do benefício, ato contínuo é reprovado no exame médico obrigatório de retorno ao trabalho, resultando no chamado "limbo" jurídico-previdenciário, como se convencionou chamar no meio trabalhista. Neste período, em que o trabalhador não trabalha, está ou estava com seu contrato suspenso e não recebe salário do empregador, instala-se uma situação de desproteção. Sem o benefício do Instituto Nacional de Previdência Social (INSS) e sem salário, eis o limbo. O objetivo do artigo foi, não só identificar o problema, mas investigar quais alternativas jurídicas o Direito tem colocado à disposição do empregado, vítima desta situação. A conclusão foi de que o Judiciário, diante da marginalização imposta pela realidade e não encontrando outro meio, tem transferido o custo aos empregadores, resultado de condenações ao pagamento salarial do período de indefinição, visando o não desamparo ao trabalhador.

Palavras-Chave: Limbo. Jurídico. Trabalhista. Previdenciário. Empregador.

\section{THE PREVENTIVE LEGAL FRAMEWORK}

\begin{abstract}
The article analyzes as legal consequences of the period in which the worker, after retirement, due to common or accidental sequelae, which require previous removal from work activities, received medical discharge. In the sequence, supposedly without being fit, it suffers the denial of the continuity of receipt of the benefit, continuous and failing any obligatory medical examination of return to work, resulting not called "limbo" legal-social security, as it was agreed to call in the labor environment. In this period, when the worker does not work, is or is with his contract suspended and no, receives the salary of the employer, a situation of unprotectedness is installed. Without the benefit of the National Institute of Social Security (INSS) and without salary, here is the limbo. The purpose of the article was, the problem was not identified, but investigating the legal alternatives or law has made available to the employee, victim of this situation. The conclusion was that the Judiciary, anticipation of the margin of taxation by reality and not found in the environment, transferred to the payment of employers, as a result of condemnations to the wage payment of the period of indefinition, aiming at not neglecting the worker.
\end{abstract}

Keywords: "Limbo". Legal. Labor. Social Security. Employer

\section{INTRODUÇÃO}

O fenômeno denominado "limbo" jurídico trabalhista, que é o período em que, após afastamento previdenciário ocorre a alta médica e na sequência o indeferindo administrativo do pedido de reconsideração, visando novo afastamento/gozo de benefício previdenciário, sem 
retorno ao trabalho, em razão de aparente continuação de inaptidão, normalmente atestada pela empresa, provoca a marginalização do trabalhador, que permanece sem recebimento de salários ou auxílio previdenciário e foi o objeto de estudo deste artigo.

O empregador atestando, por seu departamento médico, que o empregado não está apto e nem recuperado para retornar ao trabalho, ao contrário do que afirma o perito oficial do instituto previdenciário, traz uma consequência nefasta para ambas às partes. O patrão corre o risco de arcar com os custos do período de limbo e o empregado de ficar sem receber salários até que sua situação seja definida, sem a rescisão do contrato de trabalho, revelou a pesquisa.

A conclusão do trabalho foi de que a consequência jurídica dele advinda relativamente nova no que diz respeito ao ônus que tem sido transferido ao empregador brasileiro, condenado na Justiça do Trabalho a pagar os salários do período em que o trabalhador deveria estar afastado, mas recebeu alta do INSS e não voltou ao trabalho, também por falta de conhecimento jurídico adequado de seus colaboradores na linha de frente de seus departamentos jurídicos e de pessoal.

\section{METODOLOGIA}

O presente estudo se valeu do método dedutivo e dialético para, por meio de pesquisa doutrinária, jurisprudencial e legislação pertinente chegarem ao resultado. A pesquisa bibliográfica foi escassa. Há raros artigos doutrinários sobre o assunto proposto em plataformas eletrônicas. Apelou-se para a observação empírica, decorrente da experiência profissional, que advém do julgamento de vários casos concretos, numa espécie de pesquisa de campo e estudos de casos, fruto da atuação da autora como magistrada trabalhista, no enfrentamento de casos, concretos.

\section{DISCUSSÃO}

Esse período em que o trabalhador não trabalha, nem recebe, e muito menos é acolhido pelo instituto de seguridade social, objeto deste artigo, foi identificado na doutrina e jurisprudência como "limbo" jurídico previdenciário, pois o trabalhador está à margem da sociedade. Não poderia haver melhor palavra para identificar esse fenômeno. Limbo na linguagem trabalhista/previdenciária atual é um neologismo com conotação jurídica, embora antiga ${ }^{1}$ a expressão, doravante não serão utilizadas as aspas já que o leitor já se identificou com a palavra.

A intrigante inovação jurídica decorrente da realidade denominado período de limbo jurídico previdenciário, inicia-se quando o seu departamento médico constata a incapacidade, ou quando algum funcionário do departamento de pessoal recebe uma denúncia de que um trabalhador que supostamente ainda deveria estar afastado recebeu alta, mas não retornou ao trabalho. Ele supostamente continua em estado de incapacidade ou pelo menos tudo indica que sim, e em boa parte dos casos concretos reivindica o reconhecimento de sua doença/sequelas perante o Poder Judiciário na Justiça Comum (federal ou estadual a depender da localidade) e aguardará em longa caminhada a tramitação de seu processo, pois nem sempre conquista uma liminar em tutela antecipada. Nesse tempo, o trabalhador tende a ficar esperando a declaração da responsabilidade previdenciária por parte do INSS.

Contudo, há de se reconhecer a existência de casos duvidosos. Muitos trabalhadores se aproveitam do sigilo médico, que ocorre quando os afastamentos são provocados por eles mesmos, impedindo acesso à informação no site do INSS da data da alta. De boa ou má fé (infelizmente a última hipótese tem ocorrência frequente) não informam ao patrão muitas vezes propositadamente a liberação. Esse fato novo, alta sem retorno, pode ensejar a dispensa por justa

\footnotetext{
1 Sinônimo: Lugar onde se lançam coisas de que não se faz caso.

Estado de indefinição ou incerteza. 
causa, ao argumento de abandono de emprego.

Em muitos casos são perfeitamente justificáveis as ausências e o não retorno ao trabalho, mas nada justificaria a não informação da alta ao patrão. Em tese a informação sonegada comprovadamente e intencionalmente permite presumir a má fé, mormente nos casos em que o trabalhador poderia se locomover facilmente e que a doença não o impedia de fazer tal comunicação ainda que por algum integrante de sua família.

Como dito antes, nos casos em que a empresa não o encaminhou para o afastamento previdenciário a empresa não terá acesso da data da alta em acesso ao sistema. É recomendável que o patrão deva envidar esforços para descobrir se houve a alta. Por conta do alegado sigilo médico, o INSS não comunica e nem libera a informação, como esclarecido. Só o faz quando o encaminhamento para o afastamento é de inciativa da empresa. Aliás, como magistrada, enviei um ofício ao INSS para sugerir que o sigilo médico seja relevado nessas hipóteses, pois o que se quer saber é se a funcionário teve alta e não qual o motivo do afastamento. Até hoje não obtive resposta.

Entretanto, a consequência jurídica dele advinda, relativamente nova ao patrão é a condenação na Justiça do Trabalho a pagar os salários do período em que o trabalhador deveria estar afastado, porém recebeu alta do INSS e não voltou ao trabalho.

Nasce então um embate entre o INSS e a empresa que faz do trabalhador comum e verdadeiramente doente, uma marionete. Quando estes trabalhadores de bem estão doentes, o direito do trabalho por seus intérpretes não teve outra saída a não ser condenar o empregador, restando a ele perseguir o reembolso em ações regressivas.

Como já se adiantou infelizmente há trabalhadores que agem de má-fé. Fingem estar doentes, é fácil fingir. Sabe-se que estudos da medicina elementar indicam a dor como um fenômeno subjetivo e ainda não criaram um medidor de dor. Essa dificuldade de comprovação da doença ou uma dor crônica transforma-se em outro tipo de dor: de cabeça para os empregadores. E pelas condenações nas ações trabalhistas causa dor também na parte mais sensível, empresarial, o bolso!

Esta indefinição no momento em que o trabalhador antes sadio é desprezado pelo sistema, levou o judiciário trabalhista em alternativa única e criativa a reconhecer em casos que comprovadamente o trabalhador não estava em boas condições de saúde, não só a reverter o motivo da dispensa indevida (suposta justa causa por abandono), mas principalmente o direito do empregado continuar a receber os salários do período a ser custeado.

Presume-se no comportamento irregular que a culpa é exclusiva do empregador que até então usufruiu da força de trabalho de seu funcionário, ainda que a culpa possa ser atribuída ao INSS futuramente: pela sonegação do benefício - indevidamente suprimido - conforme laudos extremamente rigorosos de seus peritos médicos. Na ânsia de devolver a legião de trabalhadores de boa e má-fé que ali se misturam o INSS pode estar querendo se livrar de sua responsabilidade.

Mas é preciso reconhecer que, infelizmente, que a minoria de trabalhadores desonestos não querem ficar sem renda frente a uma ameaça de desemprego. Descobriram, assim, um caminho fácil para fraudes. Ainda assim, revelam os médicos que atuam em perícias que cerca de $70 \%$ dos pedidos de benefícios são deferidos. Ou seja, apenas uma minoria pelo que se constata não está doente e são falsos doentes. A maioria tem de fato alguma inaptidão ao trabalho parcial ou total.

Fato é que muito provavelmente os peritos médicos oficiais do INSS têm certa parcela de culpa ou não falam a mesma língua dos peritos judiciais, certamente fruto da dificuldade de uma ciência que não é exata: a medicina.

Se o número de falsos doentes infiltrados com falsas "dores", que é subjetiva, pode estar transformado o INSS em um paredão de "encostados", a justiça do trabalho também pode estar 
sendo ludibriada com laudos imprecisos e por tabela os empregadores.

O que importa na reflexão maior é que diante do indeferimento do auxílio-doença virou praxe o trabalhador entrar com ação contra o INSS para continuar recebendo benefício. Não raro, como diz o operário: a "rádio peão" já espalhou que será dispensado após a alta médica. Recorrem ao INSS sem qualquer motivo ou com medo do desemprego, principalmente quando suspeitam de alguma doença ou se já estão mal intencionados a ideia é preparar o terreno para ajuizar uma nova ação contra o patrão. A vitória será usada como prova emprestada contra os patrões na justiça comum, ou vice versa, de lá para a Justiça do Trabalho.

Por outro lado, trabalhadores realmente doentes, passarão por uma verdadeira via-sacra. Após a indevida alta do INSS ele procura um médico do SUS ou particular que confirma que ele ainda está doente. Alguns médicos conhecedores do rigor dos peritos do INSS convencidos da doença dão atestados em alguns casos para doenças que até já existiam, antes mesmo do último emprego, o que revela a fragilidade dos exames médicos admissionais e a impossibilidade de terminar com esse fenômeno a curto prazo.

Vale aqui um parêntese. Não se sabe se um exame médico admissional mal realizado é bom ou ruim para os trabalhadores. Muitos sequer conseguiriam trabalhar se passassem por exames mais rigorosos. Baseados em simples avaliação clínica, ou quando muito um simples exame de sangue, é possível omitir seu verdadeiro estado de saúde na expectativa e necessidade do emprego. O que é compreensível, pois vários trabalhadores são aprovados e considerados aptos sem estarem sadios.

Por sua vez o patrão, com escassa mão de obra principalmente braçal, tende a fazer vistas grossas. Nesta linha de raciocínio o trabalhador verdadeiramente doente, em posse deste atestado ajuíza, por seu advogado, ação na Justiça Comum contra o INSS pede, e muitas vezes consegue uma liminar, deferida pelo juiz comum e o INSS tem que "engolir" laudos contrários de seus próprios médicos concursados, aparentemente isentos (não fosse à política narrada), impondo-se a suspensão do contrato. O trabalhador, então, retoma o estado anterior de suspensão contratual, por força de ordem judicial, de modo que seu benefício e os problemas com o contrato de trabalho, que deveria estar suspenso, continuam.

Se o benefício retroage até antes da data do desligamento, nula seria a dispensa. E, partindo do pressuposto que estão verdadeiramente doentes, o laudo médico indicado pela empresa seria só um reforço.

Bom frisar que tem sido possível rescindir contratos de empregados que conquistam a aposentadoria por invalidez, com idade igual ou superior a 60 anos, pois a lei de proteção ao idoso impede que sejam submetidos a novas perícias. Sem contar que no período de limbo, a alta médica anterior aliado ao desejo de desligamento de patrão e empregado, tem ensejado homologação de acordos trabalhistas com data retroativa, de modo que permitam aos empregadores, por acordo judicial, rescindir contratos que envolvam o limbo jurídico.

É oportuno pontuar outro agravante joga os trabalhadores numa outra situação desconfortável. Os médicos contratados pelos empregadores atuando em seus ambulatórios empresariais, para evitar uma estatística ruim - o índice de acidentados aumenta o enquadramento da empresa no maior grau de risco e altera por tabela seus impostos - negam a existência de eventual doença ao argumento de que seus trabalhadores estão "aptos" e recusam a emissão da CAT (Comunicado de Acidente de Trabalho). Principalmente se houver suspeita de que o afastamento desencadeará eventual reconhecimento da existência de doenças profissionais e do trabalho, instaurando-se o caos para trabalhadores de boa-fé.

A sugestão que se deu em audiências trabalhistas, em alguns casos concretos duvidosos, foi no sentido de que o empregador oriente seus departamentos pessoais que passem a exigir que 0 doente que teve alta, mas ainda alega doença, que volte ao trabalho, ainda que em situação mais 
delicada, em serviços leves ou a domicílio, de modo que possa ser monitorado. Pode a princípio parecer algo desumano e complicado. Mas, salvo melhor juízo, não é. Patrões brasileiros, em sua maioria honesta, não exigiriam trabalho forçado se bem orientados por seus médicos. $O$ perigo de cometimento de injustiças depende da boa ou má assessoria médica.

Muitos trabalhadores na justiça do trabalho alegam que foram até o departamento de pessoal, após a alta médica do INSS e foram orientados para aguardar em casa o resultado do pedido de reconsideração, via administrativa ou judicial.

Nestas ocorrências duvidosas, por cautela, melhor seria para o empresário e para a sociedade até que o processo contra o INSS fosse definido, dependendo de seu estado de saúde, exigir que o trabalhador se apresente na empresa diariamente para bater o ponto, ou leve alguém até a residência dele de tempos em tempos para isso, nem que fosse pra ficar na empresa à disposição, sem fazer nada e, exageros à parte, até numa cadeira de roda.

Deficientes físicos também trabalham. Após uma recuperação razoável, um bom trabalhador, ainda que tenha sequelas leves, certamente se submeterá ao que lhe for sugerido, enquanto aguarda o resultado da ação previdenciária. Deste modo, justificaria o pagamento do salário do período de limbo, sem permitir que maus funcionários se aproveitassem de empregadores honestos.

Manter locais apropriados para esses doentes, descartados os portadores de doenças contagiosas ou de alto risco, quem sabe, talvez fosse um caminho a ser seguido e valesse a pena a experiência. Para alguns, não se descarta, será possível atuar em trabalhos leves, atender telefone, por exemplo.

Isso, claro, quando houver razoável dúvida sobre a existência de uma real doença. Caso desconfiem que exista mesmo uma doença mais grave, outras cautelas e todo o apoio empresarial são salutares, até para evitar pedidos de danos morais e ou materiais futuros.

Defende-se, por exemplo, as empresas ingressem nas ações de seus empregados contra o INSS, de restabelecimento do benefício ajuizado pelo trabalhador, como litisconsórcio facultativo. Evitarão, assim, as precipitadas ou infundadas alegações de abandono e/ou indenizações e as ações regressivas futuras por parte do trabalhador e do próprio INSS. O não acompanhamento pode resultar em inevitáveis perdas financeiras em condenações futuras.

Não comprovadas às doenças e monitorados os afastados, evita-se o famoso "corpo mole", eliminando a dúvida e retirando o espaço para atuação dos desonestos, como aqueles que não estão bons para o trabalho efetivo e com horário a ser cumprido, mas estão bons para fazer os famosos "bicos" em trabalhos informais, que não raro, exigem muito mais esforço do que aquele desenvolvido na empresa.

Aliás, com a disseminação de fotos nas redes sociais os empregados "encostados" tem sido vistos trabalhando em outros locais, sem registro, são denunciados e flagrados, podendo ter o benefício cancelado e até uma dispensa por justa causa, além das medidas judiciais cabíveis.

Logo, se o trabalhador não está recebendo o benefício, deve retornar ao trabalho. E a dispensa, quando não for do interesse empresarial diante da dúvida da honestidade, frente à recusa do INSS, embora possa ser feita por justa causa, no caso de abandono efetivo. No caso de dúvida razoável, é recomendável a dispensa sem justa causa. É que haverá em muitos casos dificuldade da prova da doença alegada e futura e eventualmente poderá ser comprovada uma doença (ainda que não adquirida no ambiente laboral mas existente alguma concausa/agravamento), equiparada ao acidente de trabalho (doença profissional ou do trabalho).

A opção pela dispensa por justa causa só deve ser levada a cabo se as faltas ao trabalho forem realmente injustificadas e comprovada a desonestidade, principalmente se não houver nenhum respaldo médico por parte do trabalhador faltoso.

Para evitar esse tipo de comportamento lamentável a empresa deveria contar com médicos 
mais conscientes e que evitassem fazer pré-julgamentos inadequados, contrariando laudos de seus colegas concursados em trabalho para o INSS, ou falsos diagnósticos só para, aparentemente "beneficiar" a empresa.

Mentindo ambos os lados, perde a sociedade. Sem contar que há empresário que pensa que seus departamentos médicos e de pessoal, estão economizando e atendendo orientação correta (quando não saem deles mesmos a infeliz ideia de dispensa sem respaldo técnico eficiente), O bom empresário deve estar consciente de que tal comportamento poderá, em futuro próximo, onerar ainda mais os cofres empresariais pagando mais caro logo adiante

Um vício que se inicia no exame médico admissional e termina na Justiça do Trabalho. Para evitar o abandono de emprego, cuja prova é ônus da empresa, bom lembrar que operário não lê jornal e na lei não existe tal recomendação de publicação de abandono em jornal impresso. Certamente algum dono de jornal esperto deve ter disseminado tal necessidade. Até o rádio é mais acessível para um comunicado de retorno ao trabalho. Melhor telegrama ou uma simples carta com aviso de recebimento (AR), ou até pessoalmente por parte de um assistente social ou membro do departamento de pessoal, designado para essas diligências.

Tomadas tais precauções e não haveria, pois, desculpas deslavadas em defesas empresariais que tentam escapar da condenação no período de limbo, por má orientação ao empresário que, tivesse feito diligências necessárias e poderia ter aproveitado o tempo inútil e sem prestação de serviços, ou desmascarado o falso doente. Daí sua mea culpa e a condenação na indenização dos salários do período de limbo acabo sendo transferido para a empresa, principalmente diante da omissão empresarial nas diligências para o efetivo retorno.

Não fosse a preocupação em casos de constatada a doença profissional ou do trabalho que pode ter consequências piores (condenações por danos morais e materiais, além da indenização de um ano após a efetiva alta em período posterior ao sonegado pelo INSS), não haveria dúvida alguma na possibilidade da dispensa do trabalhador, inclusive sem justa causa já que não lhe dá a lei qualquer proteção, infelizmente, em sendo auxílio doença comum.

A justa causa por outro lado, havendo comprovação de fraude e desde que não se passasse mais de um mês da alta, poderia ser aplicada com menor índice de preocupação de uma vitória nos tribunais do trabalho.

É bom que se alerte que não há estabilidade no retorno de afastamento por doenças comuns. É a triste realidade brasileira, salvo algumas negociações coletivas. Mas, algumas doenças que causem estigma ou preconceito, tem sido objeto de proteção por força de jurisprudência, como as consideradas graves, na esteira da Súmula 443 do TST:

\section{DISPENSA DISCRIMINATÓRIA. PRESUNÇÃO. EMPREGADO PORTADOR DE DOENÇA GRAVE. ESTIGMA OU PRECONCEITO. DIREITO À REINTEGRAÇÃO - Res. 185/2012, DEJT divulgado em 25, 26 e 27.09.2012 Presume-se discriminatória a despedida de empregado portador do vírus HIV ou de outra doença grave que suscite estigma ou preconceito. Inválido o ato, o empregado tem direito à reintegração no emprego.}

Além dessa possibilidade acima, somente o recebimento do auxílio-doença-acidentário, como é sabido, por acidentes típicos ou decorrentes de doenças profissionais e do trabalho (adquiridas ou agravadas pelo trabalho executado) que a ele se equiparam, repete-se, dá o direito da estabilidade de um ano após a alta médica, e não doenças comuns.

Doenças comuns, ou tem fim, ou não tem cura e o INSS deve assumir a responsabilidade pela manutenção de e empregado doravante beneficiário. Para isso todos contribuem com os impostos! Patrão e empregado, mensalmente. Só não contribui o INSS para comunicar o patrão 
que o afastamento teve um fim e que houve a alta médica, quando a iniciativa do afastamento é do empregado.

Outro agravante é que algumas empresas não querem gastar com a dispensa, fazem um novo exame e não consideram apto, reencaminham ao INSS para se "livrar" do trabalhador e o esquecem de diante da recusa inicial. Alguns realmente estão doentes e é fato que o INSS tem sido muito rigoroso e seletivo algumas vezes até desumanos, denuncia a mídia.

É neste momento que o período de limbo se torna um transtorno ao empregador. $E$ ai o custo é transferido para o patrão. Quando vitoriosos contra o INSS e conseguem o benefício, ainda mais se transformado do código 31 (doença comum) para o código 91 (doença acidentária) entram com ação contra o patrão querendo ser reintegrados ou indenizados, o pagamento dos salários do período de "limbo", do FGTS do período, etc. incluindo a indenização de 12 meses de trabalho.

E o lado ruim, principalmente quando a opção é uma justa causa desastrosa, ganhando a ação previdenciária, também o INSS o trabalhador terá subsídios para ingressar com outra ação contra o patrão, sem contar as tais ações regressivas do INSS que poderá sofrer, cujas denúncias, por convênio com o INSS e TST, os tribunais tem recomendando e devem ser feitas pela própria Justiça do Trabalho, com envio de cópias das sentenças em que foi reconhecida a culpa patronal. Punição dupla ao empregador!

Outra tarefa o difícil, dizem os especialistas, decorrem de fruição de benefícios previdenciários muito prolongados. E essa questão envolve os peritos do INSS, em confronto com os judiciais, já que s primeiros levam mais em consideração nas avaliações periciais a coerência entre o diagnóstico alegado e o tratamento proposto/realizado, bem como seu efeito na recuperação do doente. Considerando as patologias mais comuns hoje alegadas como incapacitantes por trabalhadores, na Justiça do Trabalho e, dizem, junto ao INSS, são as psiquiátricas e as ortopédicas, que ficam no topo da lista.

E seria justamente nestas doenças que estaria o calcanhar de Aquiles. E também as maiores contradições nos laudos apresentados, no confronto entre aqueles emitidos pelo INSS e os peritos da Justiça do Trabalho. Ocorrem principalmente em casos de doenças psíquicas, como Depressões e Transtornos de Ansiedade, que tem sido tratadas por anos a fio, com o uso da mesma medicação, quando se sabe, dizem os médicos especialistas, que o tempo de efeito dos antidepressivos modernos é de 40 dias, ou seja, se não resolveu em 40 dias, ou modifica-se o tratamento ou não haverá melhora, alardeiam os peritos médicos.

Ainda assim, mesmo alegando sintomas graves, o cidadão relata manutenção do mesmo tratamento, o que seria incoerente para a medicina moderna. Os sintomas podem existir, às vezes existem, afirmam os médicos, mas seguramente não seriam incapacitantes ao trabalho, pois se assim o fossem, seriam também para todas as outras atividades da vida da pessoa, o que a obrigaria a buscar um melhor tratamento realmente eficaz.

Há relatos em laudos analisados nesta pesquisa, de que a psiquiatria forense moderna, quando a pessoa encontra-se incapaz ao trabalho por motivo de doenças psíquicas, salvo raríssimas exceções, em que estará, também, incapaz todo o restante de sua vida (afazeres domésticos, cuidar de si mesma, eventos sociais etc.), o que pode e frequentemente realmente ocorre, mas por períodos curtos de tempo e não anos (exceção para casos graves e que são facilmente identificados mesmo por leigos na medicina).

Essa mesma situação é também frequente nos casos ortopédicos, onde a questão é muitas vezes pior. Os laudos médicos avaliados demonstram, por exemplo, que em tratamentos de lesões de tendão por períodos prolongados de tempo, às vezes vários anos e ainda com indicação de cirurgia para solução do caso, o que chega ao nível do absurdo, não raras vezes, considerando que a medicina indica que quando da lesão de um tendão, principalmente de articulações complexas como ombro ou joelho, que são as mais acometidas, rapidamente ( 2 a 3 meses) outro músculo 
substitui a função daquele músculo lesionado, na maioria das vezes sem prejuízo dos movimentos da articulação, ou mesmo que com prejuízo (sequela), não sendo mais possível cirurgia tendo em vista retração dos "cotos" do tendão lesionado, ou seja, ou se opera rapidamente, com solução do caso ou não se opera mais, pois o corpo humano resolverá por si só.

Resumindo, sendo a ciência médica inexata, no meio de tanta incoerência, enquanto o patrão não colocar bons profissionais na área de recursos humanos, com faro investigativo, verdadeiros detetives e o empregado honesto continuar sendo prejudicado pelos desonestos, a questão do limbo ganha ares mais cultural do que jurídico. Um empregado que nem estaria muito doente assim, não informa que dia recebeu alta, muitas vezes para ganhar tempo e pensar o que vai fazer ou em que escritório de advocacia irá correr, e enquanto a lei não vier disciplinar melhor a questão, o período de limbo tenderá a ser uma conta repassada ao empregador, quando o mau trabalhador, a falta de efetiva fiscalização do INSS, são os únicos e verdadeiros responsáveis.

\section{CONCLUSÃO}

A conclusão da reflexão crítica, a partir de leitura de raros artigos jurídicos, é que o patronato brasileiro deve cada vez mais se preocupar com o que anda fazendo seu departamento de pessoal e jurídico, ficar atento para cada afastamento previdenciário onde cada caso é um caso.

Evitar dispensar trabalhadores no período de limbo que, renegados pelas empresas, sentem-se totalmente desamparados e já começam a rondar os escritórios de advocacias, quando não são aliciados "paqueiros que o Tribunal de Ética da OAB não consegue evitar. Há trabalhadores que não são honestos

É verdade que alguns trabalhadores parecer ter receio, talvez movidos por influência religiosa, da tal lei de causa e efeito e não querem se "encostar". Fazem questão de ter alta, trabalhar, ainda que seja para tentar achar novo emprego, cativar o empregador para continuar, pois acreditam que os que fingem estar doente, acabam mesmo ficando doente. Seria uma espécie de castigo divino, o não deixa de ser um bálsamo, um consolo empresarial e em muitos casos concretos uma verdade. De tanto fingirem estar doentes, acabam ficando.

Assim comprova as ciências afins, sociologia e antropologia. A maioria dos seres humanos é honesta. Existem muitos trabalhadores bons, que trabalham até doentes, debaixo de chuva ou sol. Nesta linha de raciocínio, passa da hora de o legislativo tentar apresentar projeto de lei, que regulamente essa situação, como sugeriu a revista LTR em seu editorial de agosto de 2016.

Há de um lado, uma grande massa de trabalhadores doentes e envelhecidos. Sendo mal atendidos pelo INSS e de outro os espertos querendo se aproveitar do instituto. E em outra ponta, empresários honestos sendo enganados. De outra banda, a via sacra a qual o trabalhador tem que se submeter ao adoecer no curso do contrato de trabalho e as dificuldades da empresa para saber se de fato estão doentes ou fazendo "corpo mole" é uma realidade que não pode ser desprezada.

Os normativos internos do INSS devem ser alterados para permitir a comunicação mais eficaz aos empresários em qualquer tipo de afastamento pois, como visto no corpo do artigo, quando não é a empresa que encaminha seu trabalhador ou trabalhadora para o INSS, sendo do próprio interessado a inciativa (que infelizmente pode ocorrer quando o trabalhador sabe que está para ser dispensado obtendo a alta com dever de retornar a empresa, o empregador não saberá!

Ainda que tenha acesso, aos afastados por ela encaminhados, só se mantiver funcionário para, diariamente, verificar no site do INSS se consta na lista dos afastados pela previdência, o que é uma aberração. Resultado: ambos os trabalhadores, honestos e desonestos, procuram a Justiça do Trabalho. Muitos desligados por suposta justa causa, num "abandono de emprego" capenga, decorrente do período de limbo, algumas vezes cavado e mal fiscalizado. E pior, há casos em que o trabalhador já obteve alta há mais de meses e até anos quando não recebem tutela antecipada na justiça comum, com efeito retroativo, nem sempre coincidente com o período do limbo, ficando a 
conta da diferença a ser debitada no bolso do empregador.

O ponto nodal para identificar o período de limbo passa por um comportamento ético de todos os envolvidos já que a suposta inexistência de incapacidade exclusiva ao trabalho, na qual o cidadão estaria incapaz ao trabalho, mas capaz a outras obrigações da vida, em família ou sociais, é uma questão tormentosa na medicina e existe um confronto com os especialistas que auxiliam os juízes do trabalho. O conforto é que uma mudança de atitude e maior fiscalização pode diminuir as lides e os prejuízos atualmente enfrentados.

\section{REFERÊNCIAS}

Dicionário Aurélio Eletrônico. Publicado em: 2016-09-24, revisado em: 2017-02-27

Disponível em: 〈https://dicionariodoaurelio.com/limbo〉. Acesso em: 16 Aug. 2017

Site do Tribunal Superior do Trabalho - Súmulas. Acesso em 16.8.17

http://www3.tst.jus.br/jurisprudencia/Sumulas com indice/Sumulas Ind 401 450.html\#SUM-

$\underline{443}$

Revista Ltr, Agosto de 2016. Editorial. 